\title{
New bronchodilators in treatment of chronic obstructive pulmonary disease
}

\author{
Baran BALCAN
}

\begin{abstract}
Chronic obstructive pulmonary disease (COPD), a common preventable and treatable disease, is characterized by persistent airflow limitation that is usually progressive and associated with an enhanced chronic inflammatory response in the airways and the lung to noxious particles or gases. Clinical diagnosis of COPD should be considered in any individual, who has dyspnea, chronic cough, sputum production, and positive history of risk factors. Pharmacologic therapy can reduce COPD symptoms, reduce the frequency and severity of exacerbations, and improve health status and exercise tolerance. After cessation of smoking and life style modification, bronchodilator therapy is the first step in COPD treatment. Beside commonly used bronchodilator therapy newly developed bronchodilators started to be preferred. These drugs consist of long-acting beta2 agonist (Indacatarol, Vilanterol, Olodaterol, Abediterol), long acting muscarinic antagonism (Umeclidinium), long-acting beta2 agonist with inhaled steroid (combination of fluticasone furoate and vilanterol), long-acting beta2 agonist with a long-acting muscarinic antagonist (Fixeddose combination of indacaterol with glycopyrronium by means of breezhaler device).
\end{abstract}

Keywords: Pulmonary disease, Chronic obstructive, Bronchodilator agents

Baran Balcan

Department of Pulmonary Medicine, School of Medicine, Başkent University, Ankara, Turkey

e-mail:baranb@baskent-ist.edu.tr

\section{Introduction}

Chronic Obstructive Pulmonary Disease (COPD), a common preventable and treatable disease, is characterized by persistent airflow limitation that is usually progressive and associated with an enhanced chronic inflammatory response in the airways and the lung to noxious particles or gases [1]. Prevalence, morbidity and mortality of COPD vary across countries and different groups in the same country [2]. Prevalence of COPD is higher in male population in urban areas and the leading cause is tobacco smoking; on the other hand it is higher in female population in rural areas and the leading cause is biomass exposure [3]. Clinical diagnosis of COPD should be considered in any individual, who has dyspnea, chronic cough, sputum production, and positive history of risk factors [1]. This clinical context plus spirometric result (post-bronchodilator forced expiratory volume in 1 second (FEV1) to force vital capacity (FVC) ratio \%70) confirms the diagnosis of COPD ${ }^{4}$. Next step is the classification of the disease according to the severity of airflow limitation. The goal of COPD assessment is determining the severity of disease in order to guide the treatment [4]. Besides the severity of airflow limitations people classified according to their risk of hospitalization and severity of symptoms. Patient Group A: Low Risk, Less Symptoms, Group B: Low Risk, More Symptoms, Group C: High Risk, Less Symptoms, and Group D: High Risk, More Symptoms.

\section{Steps of COPD treatment}

- Smoking cessation; pharmacotherapy and nicotine replacement

- Pharmacologic therapy can reduce COPD symptoms, reduce the frequency and severity of exacerbations, and improve health status and exercise tolerance.

- Pharmacological treatment needs to be patient-specific; 
guided by severity of symptoms, risk of exacerbations, drug availability, and the patient's response.

- Influenza and pneumococcal vaccination should be offered to every COPD patient.

- Non-surgical bronchoscopic lung volume reduction techniques

\section{Pharmacotherapy}

- Bronchodilators

o Long acting $\beta 2$ agonist and anticholinergics are preferred to short acting ones.

o If symptoms are not improved with single agents, combination therapies should be considered.

o Inhaled bronchodilators are preferred to oral agents.

- Corticosteroids

o Long term inhaled corticosteroid treatment is preferred in patients who has severe airflow limitation, and in patients who has frequent exacerbations despite use of long acting $\beta 2$ agonist.

o Long term monotherapy with oral steroids is not recommended

o Long term single inhaled corticosteroid therapy is not recommended, instead combination with long acting B2 agonist with inhaled steroid is preferred.

\section{Newly developed bronchodilators}

\section{Long-acting beta 2 agonist (LABA)}

Indacaterol, is a novel, once daily used, long acting beta2 agonist drug. Potency of this molecule is not as effective as formoterol or salmeterol but its potency is more than albuterol. It quickly onsets its bronchodilation action, and it has a longer duration of action when compared with these three molecules. One important advantage of indacaterol is once daily use due to its longer duration of action [5]. It has not more side effects on cardiovascular, or respiratory system, when compared to other LABAs [6].

Vilanterol (GW642444), a novel LABA used via inhalation [7]. In a randomized placebo controlled study 602 COPD patients were evaluated. Patients were randomized (double-blind) to vilanterol $3,6.25,12.5,25$, or $50 \mu \mathrm{g}$ or placebo once daily for 28 days. At the end of the 4th week, improvement in the pulmonary functions is dose dependent and vilanterol 25 , or $50 \mu \mathrm{g}$ leads to statistically significant improvement in FEV1 values [8].

Olodaterol (BI1744CL) is a novel, once-daily used LABA developed with the aim of improving $\beta 2$-adrenoreceptor selectivity and intrinsic activity. Phase III pivotal trials have documented that olodaterol Respimat Soft Mist inhaler $5 \mu \mathrm{g}$ induces fast onset of bronchodilation, comparable with formoterol at day 1. Moreover, significant lung function improvements have been documented up to 48 weeks in patients with moderate to very severe COPD [9].

Abediterol is a different LABA which was compared with other LABAs et including indacaterol, olodaterol, vilanterol in vivo by Aparici. Abediterol has higher potency than other molecules in bronchodilation, its half life is longer than vilanterol but less than indacaterol and olodaterol [10]. All these novel drugs are alternative treatments in especially early stages of COPD.

Long acting muscarinic antagonism (LAMA)

Umeclidinium, a blocker of muscarinic subtype (M3) receptor, decreases the airway tone and improves the lung function. This molecule was compared with thiotropium in vivo, and it was shown that it blocked Ach-induced bronchoconstriction with longer duration of action. They suggest that umeclidinium can be used once a daily in the treatment of COPD [11].

These novel treatment options can be used especially in early stages of COPD, but better clinical outcomes can be achieved with combination of LABA with inhaler steroid, or combination of LABA with LAMA.

Long-acting beta 2 agonist with inhaled steroid

Available inhaled corticosteroid/LABA combinations for COPD require twice-daily administration. The combination of fluticasone furoate (FF) and vilanterol (VI) is being developed in a novel dry powder inhaler for the treatment of COPD with the potential for once-daily dosing. Boscia et al compared outcomes in COPD patients; one group used FF/VI combination, and the other group used placebo. Results have shown clinically and statistically significant improvements over placebo in FEV1, and there was a significant improvement in pulmonary functions test results [12].

\section{Combining a LABA with a LAMA}

Fixed-dose combination of indacaterol $110 \mu \mathrm{g} /$ glycopyrronium $50 \mu \mathrm{g}$ by means of breezhaler device 
(QVA149) has been shown in a series of clinical trials to be as safe as the single components and placebo, and more effective than placebo and the single components with regard to lung function, symptoms, and patient-oriented outcomes [13]. In addition it has better outcomes in both pulmonary functions and clinical outcomes of patients when compared to twice daily salmeterol and fluticazone combination [13]. The ENLIGHTEN study compared QVA149 with placebo; there was satisfactory improvement of FEV1, most of patients reporting no daytime symptoms, they were able to perform usual daily activities, and they did not report night-time awakenings [14]. In SHINE study they compared QVA149 with not only placebo but also with thiotropium handihaler $18 \mu \mathrm{g}$. Similar to ENLIGHTEN study better outcomes achieved in improvement of FEV1, and symptoms of patients [15]. In ILLUMINATI study they compared QVA149 with salmeterol $50 \mu \mathrm{g}$ /fluticasone $500 \mu \mathrm{g}$. In QVA149 group better spirometric results were achieved, but there was no difference between clinical outcome and improvement of symptoms [16].

\section{References}

1. Vestbo J, Hurd SS, Agusti AG, Jones PW, Vogelmeier C, Anzueto A, Barnes PJ, Fabbri LM, Martinez FJ, Nishimura M, Stockley RA, Sin DD, Rodriguez-Roisin R. Global strategy for the diagnosis, management, and prevention of chronic obstructive pulmonary disease: Gold executive summary. Am J Respir Crit Care Med 2013;187:347-65.

2. Lopez AD, Shibuya K, Rao C, et al. Chronic obstructive pulmonary disease: Current burden and future projections. Eur Respir J 2006;27:397-412.

3. Mathers CD, Loncar D. Projections of global mortality and burden of disease from 2002 to 2030. PLoS Med 2006;3:e442.

4. Wen FQ, He B. [interpretation of global strategy for the diagnosis, management and prevention of chronic obstructive pulmonary disease (gold) (revised 2011)]. Zhonghua Yi Xue Za Zhi 2012;92:939-40.

5. Sturton RG, Trifilieff A, Nicholson AG, Barnes PJ. Pharmacological characterization of indacaterol, a novel once daily inhaled 2 adrenoceptor agonist, on small airways in human and rat precision-cut lung slices. J Pharmacol Exp Therap 2008;324:270-5.
6. Bauwens O, Ninane V, Van de Maele B, et al. 24-hour bronchodilator efficacy of single doses of indacaterol in subjects with copd: Comparison with placebo and formoterol. Curr Med Res Opin 2009;25:463-70.

7. Harrell AW, Siederer SK, Bal J, et al. Metabolism and disposition of vilanterol, a long-acting beta(2)-adrenoceptor agonist for inhalation use in humans.Drug Metab Dispos: The Biological Fate of Chemicals 2013;41:89-100.

8. Hanania NA, Feldman G, Zachgo W, et al. The efficacy and safety of the novel long-acting beta2 agonist vilanterol in patients with copd: A randomized placebo-controlled trial. Chest 2012;142:119-27.

9. Matera MG, Ora J, Cazzola M. Differential pharmacology and clinical utility of long-acting bronchodilators in copd - focus on olodaterol. Therapeut Clin Risk Manag 2015;11:1805-11.

10. Aparici M, Gavalda A, Ramos I, et al. In vitro and in vivo preclinical profile of abediterol (las100977), an inhaled long-acting beta2-adrenoceptor agonist, compared with indacaterol, olodaterol and vilanterol. Eur J Pharmacol 2016;770:61-9.

11. Salmon M, Luttmann MA, Foley JJ, et al. Pharmacological characterization of gsk573719 (umeclidinium): A novel, long-acting, inhaled antagonist of the muscarinic cholinergic receptors for treatment of pulmonary diseases. J Pharmacol Exp Therapeut 2013;345:260-70.

12. Boscia JA, Pudi KK, Zvarich MT, Sanford L, Siederer SK, Crim C. Effect of once-daily fluticasone furoate/vilanterol on 24-hour pulmonary function in patients with chronic obstructive pulmonary disease: A randomized, threeway, incomplete block, crossover study. Clin Therapeut 2012;34:1655-1666.e1655

13. Rossi A, Zanardi E, Poletti V, Cazzola M. Clinical role of dual bronchodilation with an indacaterol-glycopyrronium combination in the management of copd: Its impact on patient-related outcomes and quality of life. Int J Chron Obstr Pulmon Dis 2015;10:1383-92.

14. Rodrigo GJ, Plaza V. Efficacy and safety of a fixed-dose combination of indacaterol and glycopyrronium for the treatment of copd: A systematic review. Chest 2014;146:30917.

15. Bateman ED, Ferguson GT, Barnes N, Gallagher N, Green Y, Henley M, Banerji D. Dual bronchodilation with qva149 versus single bronchodilator therapy: The shine study. Eur Respir J 2013;42:1484-94.

16. Vogelmeier CF, Bateman ED, Pallante J, et al. Efficacy and safety of once-daily qva149 compared with twice-daily salmeterol-fluticasone in patients with chronic obstructive pulmonary disease (illuminate): A randomised, double-blind, parallel group study. Lancet. Respir Med 2013;1:51-60. 